\title{
RUIDO VISUAL: LA SATURACIÓN DE IMÁGENES EN LA CONTEMPORANEIDAD
}

\section{Edurne González Ibáñez}

Universidad del País Vasco /Euskal Herriko Unibertsitatea. Dpto. Arte y Tecnología

\section{Resumen}

La actualidad está marcada por la superproducción y consumo de imágenes que constituyen uno de los pilares de lo que se ha denominado cultura visual. La velocidad con la que actualmente se re-producen las imágenes, satura nuestra capacidad de discernir e interpretar, generando situaciones que desbordan nuestro poder de asimilación, y anula los tiempos para el análisis que precisa una mirada crítica. Ante esta espectacular densificación de la iconosfera, planteamos el concepto de ruido visual como metáfora de esta circunstancia de sobreexposición al entramado audiovisual a la que nos vemos sometidos continuamente. La aceleración de los acontecimientos y las transformaciones tecnológicas, así como sus consecuencias, son el punto de partida de algunas propuestas que desde el ámbito de la práctica artística, visibilizan ciertas problemáticas a las que se enfrenta una sociedad marcada por el uso excesivo (abuso) de imágenes y la reiteración de contenidos.

Palabras claves: IMAGEN; SUPERPRODUCCIÓN; DROMOLOGÍA; RUIDO VISUAL

\section{VISUAL NOISE: THE SATURATION OF IMAGES IN CONTEMPORANEITY}

\section{Abstract}

Contemporary society is defined by the over-production and consumption of images, which configure one of the foundations of what has been called visual culture. The speed of the current re-production of images saturates our capacity to discern and interpret, thus leading to situations in which our ability to assimilate is overflown and we lack the substantial time for developing a critical gaze. In this situation of spectacular densification of the iconosphere, we propose the term "visual noise" as a metaphor of this circumstance of over-exposition to the audiovisual maze, to which we find ourselves continuously subjected. The acceleration of events and the technological transformation, together with their consequences, have therefore become departing points for certain artistic practices. These practices aim at making visible the issues that a society burdened with the over-use (abuse) of images and the repetition of contents must endure.

Keywords: IMAGE; OVER-PRODUCTION ; DROMOLOGY; VISUAL NOISE

González Ibáñez, Edurne. 2015. "Ruido visual: la saturación de imágenes

en la contemporaneidad”. AusArt 3 (2): 226-235. D0I:

10.1387/ausart.15964

\section{AUSART}


La trayectoria tecnológica de la cámara se ha ido concretando a partir de una secuencia de eventos, en la que diversas piezas encajan para configurar un procedimiento por el cual se pasa de la generación de una proyección en la cámara oscura, a la captura y fijación de la misma. De este modo, cámara y químicos se conjugaron para dar lugar a la fotografía a principios del siglo XIX. Al igual que sucedió con las primeras grabaciones de sonido que permitieron reproducir una nota percutida con anterioridad, la cámara permitía registrar un instante luminiscente para su observación posterior, contribuyendo a generar situaciones "eternamente" repetibles.

A lo largo del siglo XX la cámara se convirtió en un símbolo de modernidad, un reflejo del desarrollo de la sociedad industrial preocupada por los sistemas de producción. La historia de la fotografía se encargó de enfatizar el análisis de los procesos como parte fundamental para comprender la génesis de la imagen técnica. A finales de siglo, el interés general por el modo de proceder del sistema analógico se fue desvaneciendo a medida que se expandía lo digital como paradigma desde el que construir la fotografía en particular y la imagen en general.

Ya en el siglo XXI, la fotografía digital se convierte en una consecuencia de un modelo de sociedad en la que los intervalos se suprimen, donde las relaciones suceden en y desde la distancia, constituidas desde el marco de un sistema proclive a que los intercambios y las transacciones económicas sucedan por vía telemática. La actualidad marcada por la superproducción y consumo de imágenes constituye uno de los pilares de lo que se ha denominado cultura visual. Lo relevante en este hecho es que la mayoría de los que toman y comparten habitualmente instantáneas ya no requieren de una cámara, sino que disponen de otros aparatos que han ido incorporando la posibilidad del registro audiovisual pero sustituyendo al instrumento fotográfico como tal. La unicidad de la cámara como objeto se desintegra, resituándose como una parte del compendio tecnológico que ofrecen diversos dispositivos como smartphones, tablets, portátiles, relojes y gafas desde los que obtener, editar y difundir múltiples contenidos.

Ampliadas exponencialmente las posibilidades de registro, el modo en el que se visualiza este material también cambia, la pantalla se convierte en la superficie por donde circulan las imágenes digitales. Joan Fontcuberta alude a la desmaterialización de la fotografía tradicional que ocupaba un lugar. “... la impresión de la imagen sobre un soporte físico ya no es imprescindible para que la imagen exista, por tanto, la foto digital es una imagen sin lugar y sin 
origen, desterritorializada, no tiene lugar porque está en todas partes" (Fontcuberta 2015, 13).

Se plantea de esta manera, otro modo de relacionarse no solo con la fotografía, que ha pasado de un espacio tópico -el papel- a otro teletópico -la pantaIla-, sino con la circunstancia que motivaba la decisión de apretar el disparador de una cámara. Si bien nuestra interpretación de muchas de las imágenes siempre ha dependido de una relación indirecta con lo que en ellas se presentaba; hoy, estamos acostumbrados a la lejanía o a una desvinculación total con el contenido de las ventanas-pantalla, desde las cuales estamos consolidado gran parte de nuestro saber sobre los acontecimientos.

Esta cuestión se entiende a partir del grado de desindexilización ${ }^{1}$ de las imágenes, la pérdida del referente. Los siempre atribuidos valores de verdad, registro y memoria se escapan del sentido de la imagen digital, que ya no se basa en las funciones atribuidas a la fotografía tradicional, por las que se garantizaba la autentificación de la experiencia, la constatación del hecho y su supuesta veracidad. La deriva digital nos conduce a terrenos híbridos donde hace tiempo se agotó la intención de re-presentar la realidad para cimentarla y fundarla de nuevo a través de ficciones. Una progresiva sustitución de la realidad por la imagen de sí misma, nos conduce a una circunstancia donde la atención se dirige hacia la copia y no al original, estructurando y dando otro sentido a nuestra experiencia de lo real.

Otra consecuencia directa de los efectos de la inmersión en el sistema digital consiste en la posibilidad de "publicar", es decir hacer público, esos contenidos. De este modo, los consumidores de imágenes se han convertido progresivamente en productores incesantes, aparentemente asumiendo esta posibilidad de realizar, manipular y distribuir archivos multimedia.Por otro lado, los recursos y utilidades que ofrecen estos aparatos han multiplicado la posibilidad de que el usuario sea bombardeado por numerosas imágenes/informaciones no deseadas, contribuyendo a una espectacular densificación de la iconosfera.

Este hecho nos plantea una serie de preguntas sobre el modo en el que, instantáneamente, se re-producen, consumen, se descartan o se viralizan las imágenes en la contemporaneidad. Demasiada información visual, nos sitúa ante el peligro de un "acto de olvido" que Vilém Flusser describe como la pérdida de la capacidad para interpretar las imágenes omnipresentes que nos rodean y que están reestructurando nuestro contexto, convirtiéndolo en un escenario global. "(Las imágenes) Parecen encontrarse en el mismo nivel de 
realidad que su significado. Por tanto, lo que en ellas se ve no parecen ser símbolos que necesiten ser descifrados, sino síntomas del mundo, a través de los cuales se reconoce, aunque indirectamente, el mundo (...) (El contemplador) las cree como a sus propios ojos. Consecuentemente, no las critica como imágenes, sino como cosmovisiones -si es que las critica-. Su crítica no es un análisis de su generación, sino un análisis del mundo. La falta de crítica de las imágenes técnicas debe resultar peligrosa (...) porque la "objetividad" de las imágenes técnicas es un engaño; pues no sólo son simbólicas, como todo tipo de imágenes, sino que representan complejos simbólicos mucho más abstractos que las imágenes tradicionales" (Flusser 2001, 18).

Sujeto y objeto se ven emparentados cada vez más estrechamente en una relación que va difuminando las fronteras entre cuerpo y prótesis, incorporando la herramienta tecnológica como una prolongación del hacer cotidiano. Las campañas publicitarias tanto de los instrumentos fotográficos como de otro tipo de equipos electrónicos, denotan esta fusión que planteamos. Muchos de sus eslóganes se valen de una simbiosis en la que resulta complejo diferenciar entre el ejecutor de la acción de captura y el propio dispositivo. "I am Nikon" ${ }^{2}$ propone al operador de la cámara como parte integrada en el aparato, o en el caso "Shot on iPhone 6" 3 pone en valor las prestaciones del producto como sustituto competente de una cámara profesional, que harán que el sujeto obtenga "espectaculares" resultados.

Superado el paso de la vida analógica a la digital, el cuestionamiento del proceder tecnológico queda relegado a un segundo plano. Nos encontramos ante un quiebre radical en el modo de relacionarnos y entender la tecnología, que dificulta y desborda nuestra capacidad de asimilar la construcción de la imagen.

Replantearnos qué tipo de imágenes generamos y cómo se elaboran, cuestionarnos la simultaneidad de sus procesos de génesis, su transformación constante y divulgación, son preguntas que no tienen demasiada presencia en la ajetreada actividad de nuestros días. A pesar de incorporar desde la más temprana edad el uso de los nuevos medios, el aprendizaje necesario para dimensionar su alcance, es insuficiente y precario. De esta manera, el tan necesario ejercicio para abordar la complejidad del significado que acumulan las imágenes digitales, queda suprimido.

También resulta conveniente, señalar el modo en el que tanto la cámara como el resto de los dispositivos multimedia que utilizamos, se constituyen a partir 
de una serie de relaciones entre la industria que los produce y el complejo contexto socioeconómico en el que están insertos. No son herramientas neutrales, sino portadoras de una programación tras la que se ocultan intenciones e intereses. "Los aparatos son cajas negras que simulan el pensamiento en forma de un juego de combinación con símbolos similares a los números y, a la vez, lo mecanizan de modo que en el futuro los seres humanos serán cada vez menos competentes para él, teniendo que dejar que los aparatos piensen en su lugar" (Flusser 2001, 32).

Tanto el hardware como el software son portadores de una serie de especificidades que dirigen y controlan nuestro interés. Los menús de sus aplicaciones muestran variadas posibilidades, que resultan ser rápidamente finitas. El aspecto visual que denominan "amigable", se renueva en un permanente cambio de apariencia, que tiene como claro objetivo atraparnos en la ilusión que produce la novedad. Y toda una larga lista de características que "embellecen" la interfaz de los dispositivos, en realidad, encierran estrategias que nada tienen que ver con la "mejora de la experiencia" del usuario, sino que condicionan nuestro ritmo, entretienen nuestra mente y distorsionan el modo de mirar y dirigirnos al mundo.

A partir de los cada vez más difusos límites entre sujeto, objeto y soporte se instaura un modelo marcado por la idea de progreso, fundamentada en la dromología de Paul Virilio. Quien analiza la aceleración de los acontecimientos y las transformaciones, así como sus consecuencias en la elaboración de conocimiento. "Las sociedades (...) se constituyen en torno a la riqueza pero se olvida que ésta va unida a la adquisición de velocidades superiores, que permiten el domino de los pueblos, de los territorios y de la producción: son sociedades dromóticas" (Virilio 1995, 72).

Los protocolos relativos al modo en el que se configura la velocidad en la producción de la imagen, responden a un modelo que trata de ajustarse al devenir de un mundo en progresiva aceleración. La supremacía de la velocidad y de lo instantáneo, hacen que habitualmente perdamos de vista los contornos de nuestro contexto inmediato, y convengamos en privilegiar el interés por los productos culturales de un sistema globalizado, en detrimento de atender nuestro entorno próximo. "El pase de una "velocidad relativa" a una "velocidad absoluta”, reduce la vida pública de los ciudadanos al reducir el espacio, y tiende a confinarlos en la inercia de la espera de ver llegar lo que aparece en pantalla. Más "contemporáneos" que ciudadanos, lo cercano o "actual" pierde interés en beneficio de lo lejano o "virtual". La vecindad territorial de la "polis", 
de la cual somos "actores", es sustituida por una vecindad transnacional de una ciudad mediatizada en la cual somos "espectadores" (Benegas 1995, 67).

La rapidez con la que actualmente se re-producen las imágenes, satura nuestra capacidad de discernir y clasificar, generando situaciones que desbordan nuestro poder de asimilación. Hacemos alusión al concepto de ruido visual como metáfora de esta circunstancia de sobreexposición al entramado audiovisual a la que nos vemos sometidos continuamente, convirtiéndonos en sujetos en riesgo de padecer una "ceguera" por saturación.

La sobreabundancia se podría entender como un flujo diverso y heterogéneo, como una rica producción que nos condujera, más allá de una primera aproximación sobre su origen, a enriquecer y ampliar nuestro conocimiento. Por el contrario, constatamos cómo esta promesa de diversificación se convierte en una combinatoria que reitera ciertos contenidos y nos dirige la mirada hacia una misma escenificación en la que cambian pocos elementos. Este hecho se traduce en una especie de imágenes-spam, de las que Hito Steyerl $(2014,182)$ nos señala una interesante dualidad: la supervisibilidad y la invisibilidad. Tal vez, esta característica pueda considerarse como el punto ciego de la supuesta visión panóptica que nos ofrecen nuestras ventanas-pantalla del mundo, y supone una parte inseparable de nuestra vida cotidiana en el medio digital.

Resulta imposible negar que nos encontremos expuestos ante una multitud de estímulos visuales que convenimos en denominar información. Éstos, en vez de motivar la respuesta de los sujetos, agotan su capacidad de reacción. $Y$ tal como apuntara Aldous Huxley en "Un mundo feliz", nos conduce a una reducción de nuestros focos de interés en vez de potenciarlos, confinándonos a un estado de pasividad.

Ciertamente, las imágenes nunca fueron objetivas, neutras ni carentes de ideología, siempre acecharon nuestra mirada para provocar lecturas intencionadas. Ni la fotografía analógica, vinculada como decíamos a la constatación de un hecho, ni la fotografía digital, escapan de ser el resultado de una "manipulación". Georges Didi-Huberman pone el acento en la importancia del gesto de cómo abrir los ojos. "Todas las imágenes del mundo son el resultado de una manipulación, (...) La cuestión es, más bien, cómo determinar, cada vez, en cada imagen, qué es lo que la mano ha hecho exactamente, cómo lo ha hecho y para qué, con qué propósito tuvo lugar la manipulación. (...) Frente a 
cada imagen, lo que deberíamos preguntarnos es cómo (nos) mira, cómo (nos) piensa y cómo (nos) toca a la vez" (Didi-Huberman 2013, 14).

El ámbito de la práctica artística no se encuentra al margen de esta circunstancia de carácter omnipresente, que a su vez entrega a la escena de la producción contemporánea, una multiplicidad de posibilidades que nos interpelen sobre las cuestiones abordadas. A través de algunos ejemplos específicos, proponemos una pequeña muestra de algunas reflexiones artísticas ante el panorama al que se enfrenta una sociedad marcada por la reiteración y el uso excesivo (abuso) de imágenes.

Situados ante esta circunstancia de invisibilidad por exceso, desde el análisis sobre los nuevos paradigmas que estructuran nuestra realidad postfotográfica, hacemos alusión a un trabajo que forma parte de la investigación doctoral de Iraida Lombardía. En su proyecto SD \& CF, encierra un grupo de tarjetas de memoria repletas de imágenes en cajas de plexiglás para que no puedan ser visualizadas, colocándonos ante la ausencia de lugar de la fotografía digital. A su vez, nos invita a definir mentalmente estas instantáneas, a partir de los datos que describe una cartela en la que indica el número de archivos, el lugar y la fecha donde fueron realizados.

La sugerente idea de la imagen latente ha sido y continúa siendo en muchas ocasiones, el punto de partida desde el que los artistas se han plantado frente al exceso visual, cuestionado cómo vemos, qué queremos ver, qué nos hacen ver, invitándonos a pensar en imagen sin imagen. En la reciente $56^{\mathrm{a}}$ Bienal de Venecia, Joana Hadjithomas y Khalil Joreige nos convocaban a 177 días de performances en las que repensar, reconstruir y deambular por diversos escenarios desde la imaginación, con su trabajo "Latent Images, Diary of a Photographer, 2009-2015. (part III of the project Wonder Beirut) a través de las descripciones orales del diario fotográfico.

Por otro lado, la concepción de cámara como extensión del cuerpo, en el caso de la artista venezolana Alejandra Martin Bonilla, supone la posibilidad de hacer frente a sus problemas oculares que no le permiten tener una visión estereoscópica. Para ella, la cámara es una prótesis que le permite duplicar su visión y conseguir instantáneas perfectamente enfocadas, a partir del ensamblaje de numerosos disparos en programas de edición. En su investigación doctoral aborda cuestiones vinculadas a una enfermedad denominada prosopagnosia, por la cual se padece de una interrupción selectiva de la percepción que impide reconocer el rostro de las personas y el propio. Los síntomas de 
esta dolencia podrían servir para analizar metafóricamente algunos males de la sociedad contemporánea, donde la falta de encuadre y nitidez se suplen a través de la superposición de realidades fragmentadas que acaban configurando lo que venimos denominamos ruido visual.

Otras propuestas se valen de la propia fotografía como tema y experiencia, la metafotografía nos plantea la idea, el concepto y la resolución como parte de un todo, incluso para llegar a la negación absoluta. El agotamiento visual materializado en el proyecto "No cámara" es parte del resultado de un proceso, en el que el artista Mr. Pippin, aborda la problemática de la saturación de imágenes como sustitutos de la realidad. Su propuesta se acerca a un ejercicio de oposición al proceso fotográfico, por el cual construye cámaras que por su diseño y estructura, se anulan a sí mismas, haciendo incompatible su función como instrumento de captura.

\section{CONCLUSIÓN}

Finalmente, podemos constatar cómo la complejidad de la composición de la iconosfera se debe a la interacción entre diversos factores, que se desarrollan a partir de la velocidad en la que se suceden los acontecimientos en la actualidad. Entre ellos, destacamos la progresiva desintegración de los contornos entre sujetos y dispositivos que se observa en la proliferación del uso de aparatos, que también realizan funciones que específicamente se le atribuían a la cámara fotográfica y que ahora pueden ser utilizadas por todos los usuarios. Esta cuestión que democratiza la posibilidad de generar archivos audiovisuales, así como difundirlos, también somete al individuo a las condiciones impuestas por los automatismos y funciones predeterminadas. $\mathrm{Y}$, aunque parezcan infinitas las opciones que ofrecen estos equipos, quedan bastante acotadas las variables de juego en la práctica.

A estos hechos se suma otra característica de la imagen digital, no precisa de su fijación en papel para ser re-producida y provoca una tendencia hacia la des-materialización, tanto de los instrumentos con los que se capturan las instantáneas como la reconversión de su soporte físico tradicional en la pantalla. Al no resultar imprescindible el proceso de impresión, la enorme cantidad de pixeles constituidos como imágenes aumenta notablemente debido a que, "supuestamente", no generan coste y no ocupan un lugar. Estas variables 
favorecen que se distribuyan en un constante flujo de información que recorre los canales de comunicación que ofrece Internet. La Red, a pesar de facilitar el intercambio de saberes de primera mano y la posibilidad de diversificar de los puntos de vista, tiene su contrapartida en la saturación producida por la reiteración de ciertos contenidos que circulan viralmente hasta agotarse.

Como hemos analizado en los proyectos mencionados que aluden a esta realidad postfotográfica, desde el ámbito de la práctica artística encontramos propuestas que replantean las características asociadas a estas ideas en torno al concepto de ruido visual como consecuencia de la circunstancia de sobreexposición al entramado audiovisual. Desde su conceptualización y a través de diversas maneras de formalizarse, permiten repensar nuestra posición como sujetos consumidores a la vez que productores de imagen. Condición que nos ubica explícitamente en el bucle infinito en el que hoy nos encontramos, situándonos dentro de la imposible lógica de nuestro sistema digital que cada día nos arroja, una imagen de la imagen de la imagen...

\section{Referencias}

Benegas, Noni. 1995. "Teoría de la velocidad". En Media Culture, Claudia Giannetti, ed., 61-69. Barcelona: Associació de Cultura Contemporània l'Angelo

Claudia Giannetti, ed. 1995. Media Culture. Exposiciones del proyecto TransForma, Arte y Nuevas Tecnologías en España (sept.-nov. 1995). Barcelona: Associació de Cultura Contemporània l'Angelo

Didi-Huberman, George. 2013. "Cómo abrir los ojos". Prólogo a Desconfiar de las imágenes. Harun Farocki, traducción Julia Giser. Buenos Aires: Caja Negra

Farocki, Harun. 2013. Desconfiar de las imágenes. Traducción, Julia Giser. Buenos Aires: Caja Negra

Flusser, Vilém. 2001. Una filosofía de la fotografía. Traducción, Thomas Schilling. Madrid: Síntesis

Fontcuberta, Joan. 2015. La cámara de Pandora: La fotografi@ después de la fotografía. Barcelona: Gustavo Gili

Gubern, Román. 1987. La mirada opulenta: Exploración de la iconosfera contemporánea. Barcelona: Gustavo Gili

Hernández-Navarro, Miguel Ángel et al. 2008. Heterocronías: Tiempo, Arte y Arqueologías del presente. Murcia: Cendeac

Huxley, Aldous. (1932) 2004. Un mundo feliz. Traducción de Ramón Hernández. Madrid: Debolsillo Contemporánea

Ribalta i Delgado, Jorge, ed. 2004. Efecto Real: Debates posmodernos sobre fotografía. Traducción de Elena Llorens Pujol. Barcelona: Gustavo Gili 
Steyerl, Hito. 2014 Los condenados de la pantalla. Traducción, Marcelo Expósito. Buenos Aires: Caja Negra

Virilio, Paul. 1995. "Dromología, la lógica de la carrera: Una conversación con Giacio Daghini". En Media Culture, exposiciones del proyecto TransForma, Arte y Nuevas Tecnologías en España, sept.-nov. 1995. Claudia Giannetti, ed., 78-84. Barcelona: Associació de Cultura Contemporània l'Angelo

- 2005. Lo que viene. Traducción de Miguel Lancho. Madrid: Arena

Virilio, Paul \& Enrico Baj. 2010. Discurso sobre el horror en el arte. Traducción de Giulio Scafa Madrid: Casimiro

Notas

1 Término utilizado por Joan Fontcuberta en La cámara de Pandora: La fotografi@ después de la fotografía. (Barcelona: Gustavo Gili, 2010-2015).

2 Nikon, Marketing Tools https://press.mynikonlife.com.au/marketing-tool/index/slug/Nikon\%2BLogos (Acceso nov. 2015).

3 Apple, iPhone World Gallery. www.apple.com/es/iphone/worldgalleryl (Acceso jul. 2015). Redirigido a: http://www.apple.com/mx/iphone/world-gallery/films/, galería de videos hechos con el producto mencionado. 